\title{
Surface Analysis, Mechanical and Corrosion Behavior of Welded Steel in 1M HCl Corrosive Media with Epoxy/Alumina Coating
}

\author{
Younes Ziat ${ }^{1}$, Maryama Hammi ${ }^{1,2, *}$, Zakaryaa Zarhri ${ }^{3, *(D)}$, Ousama Ifguis 4 \\ 1 Engineering and Applied Physics Team (EAPT), Sultan Moulay Slimane University, Beni Mellal, Morocco \\ 2 University of Mohammed 5 - Rabat, Morocco \\ 3 CONACYT-Tecnológico Nacional de México/I.T. Chetumal; Insurgentes 330, Chetumal, 77013, QR, Mexico \\ 4 Team of Analytical \& Computational Chemistry, Nanotechnology and Environment, Faculty of Science and Technics, \\ Sultan Moulay Slimane University, Beni Mellal, Morocco \\ * Correspondence: maryama.hammi@um5s.net.ma (M.H.); z.zarhri@gmail.com (Z.Z)
}

Scopus Author ID 57219546880

Received: 2.06.2021; Revised: 8.07.2021; Accepted: 11.07.2021; Published: 9.08.2021

\begin{abstract}
This work is devoted to investigating the effect of arc welding energy on microstructures and mechanical properties of steel 316L. This later is very useful in industrial, infrastructure transportation, containers shipping, and almost logistic applications. For that reason, five samples of welded steel 316L were carried out based on many parameters to reveal some properties (microstructure, mechanical, corrosion resistance, etc.). To reveal the anticorrosion efficiency. The epoxy/Alumina composite coating on welded steel $316 \mathrm{~L}$ is tested in $1 \mathrm{M} \mathrm{HCl}$ acidic media. This manipulation shows excellent corrosion resistance thanks to epoxy/Alumina coated. The choices of this coating are based on the environment, cost and safety. The used epoxy is only degrading with fire but not toxic. Also, it is not a costly method, and it is widely used and performed. Impedance studies on samples of welded steel 316L were conducted in $1 \mathrm{M} \mathrm{HCl}$ media. The results showed that transfer resistance is increasing with the increase of welding energy. This result was assessed by potentiodynamic polarization measurements indicating a noticeable reduction of current densities with welding energy decrease. The scanning electron microscope (SEM) micrograph was undertaken in order to check how far the studied samples are protected by the used coating in such aggressive media.
\end{abstract}

Keywords: welded steel; metallurgical; epoxy composite; electrochemical measurements; aggressive media

(C) 2021 by the authors. This article is an open-access article distributed under the terms and conditions of the Creative Commons Attribution (CC BY) license (https://creativecommons.org/licenses/by/4.0/).

\section{Introduction}

The inhibition efficiency is still a challenge to protect the metallurgic surfaces since it is connected to many parameters such as environmental appropriateness, the reasonable cost of elaboration, and applicability. Many works are devoted to designing the inhibitors for metals and alloys such as copper [1-4], silver [5], magnesium alloy [6], aluminum [7], and steel [812]. The epoxy - coating modified with graphene is a suitable composite against the corrosion surface of the copper in marine media [1]. For the mild steel, the inhibition potential of inorganic glass with $25 \% \mathrm{P}_{2} \mathrm{O}_{5}-25 \% \mathrm{CaO}-50 \% \mathrm{~K}_{2} \mathrm{O}$ composition in $1 \mathrm{M} \mathrm{HCl}$ solution shows that the optical structural analysis provides good protection to the surface [8].

Since the welded steel 316L protected by the proposed Epoxy/Alumina coating is a matter of this paper, some investigations in terms of the welding [13-17] are worthy of 
mentioning. Experimental outcomes exhibited that when the forging pressure increases, the hardness of the weld interface increases where the tensile strength decreases [18]. The electrochemical and microstructural behavior of welded pipe "A106 - Gr.B" and 316Lwith Ni alloys were studied, for weld joint, the microstructure of the heated affected zone on root weld causing an intense grain refinement and polygonal ferrite and pearlite formation by welding heat cycle changed [19]. Also, the effect of microstructure on contact angle and corrosion of ductile Iron-Graphite composite was studied "ferrite, pearlite, and graphite". Pearlite has been proven to be more susceptible to corrosion than ferrite and graphite. A higher proportion of pearlite in the microstructure can be detrimental to the material's corrosion resistance [20]. The aim of the present work is to investigate the surface, mechanical, and corrosion behavior of welded steel 316 in 1M HCl media with Epoxy/Alumina coating, in which the epoxy/Alumina composite coating on welded steel $316 \mathrm{~L}$ is excellent corrosion resistance.

The rest of this paper is arranged as follows, in which section 2 is based on the mechanical and chemical preparation of welded steel. Then, section 3 is intended for the anticorrosion study of samples welded in $1 \mathrm{M} \mathrm{HCl}$ media, electrochemical, potentiodynamic polarization measurements, and scanning electron microscope analyzes. This process shows a correlation between mechanical and electrochemical properties.

\section{Materials and methods}

\subsection{Mechanical and chemical preparation of welded steel $316 \mathrm{~L}$.}

This study describes the influence of a thermal cycle change on the microstructure and mechanical properties of a welded steel joint. For this purpose, a similar filler metal was used. To do so, the following steps have been processed:

1st: Identification of the base metal.

2nd: Welding the samples.

3rd: Metallurgical and mechanical characterizations.

For this purpose, five weld samples were prepared by cutting ingots of the studied steel in ten portions of almost equal length (the length is $5 \mathrm{~cm}$ ) and surface area, which was associated in five pairs, see Figure 1.

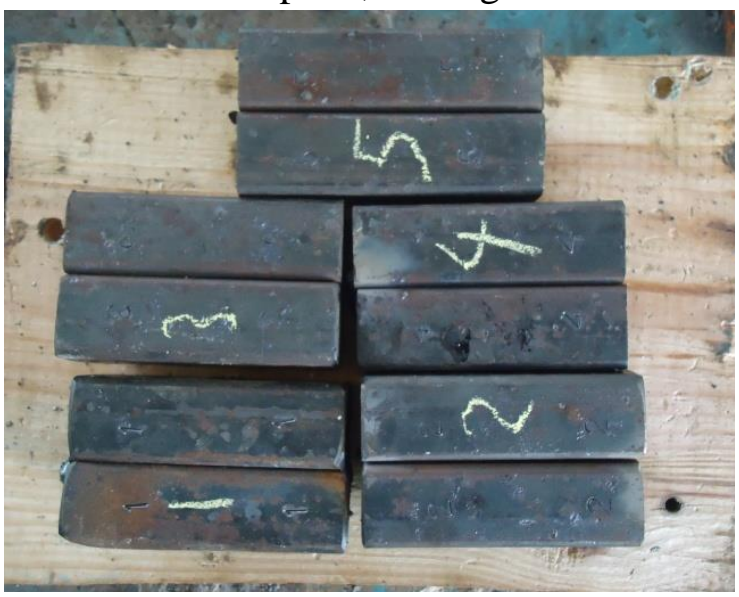

(a)

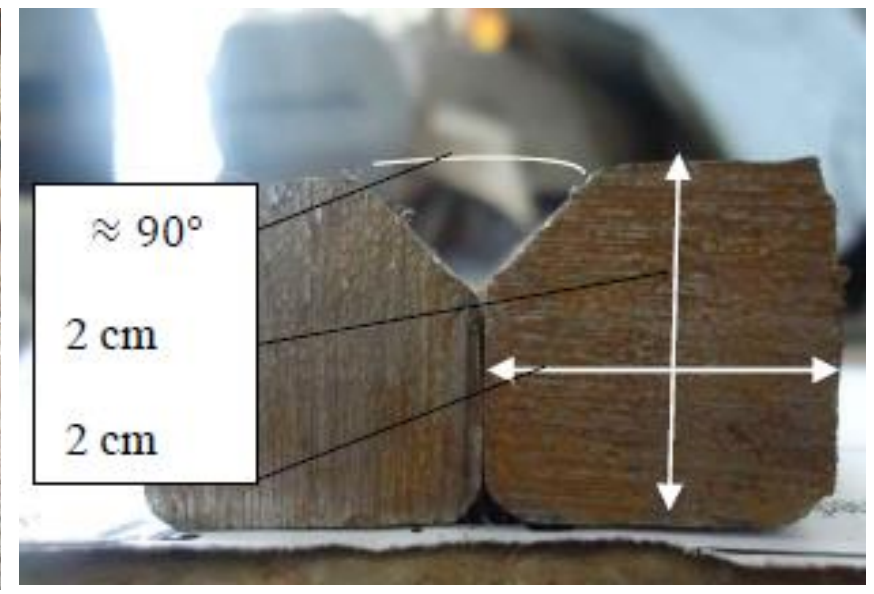

(b)

Figure 1. (a) Before welding; (b) Welding joints: $\mathrm{Y} \approx 90^{\circ}$.

For all the samples, the mechanical preparation took place by automatic rotating disc to polish the surfaces of the steel ingots using abrasive papers, the aim being to remove the roughness. Then, the prepared steel surfaces were followed by the electrolytic polishing using 
a mixture of orthophosphoric acid: $\mathrm{H}_{3} \mathrm{PO}_{4}(95 \%)$ and sulfuric acid $\mathrm{H}_{2} \mathrm{SO}_{4}(5 \%)$. To highlight the presence of the pearlite, a chemical etching is performed. It is carried out using ethanol $(95 \%)$ and nitric acid $\mathrm{HNO}_{3}(5 \%)$.

\subsection{Impact of welded energy on microstructure and mechanical properties}

After each polishing, the appearance and the presence of the existing phases are examined using an optical microscope. See Figure 2 of the steel surface before the welding process.
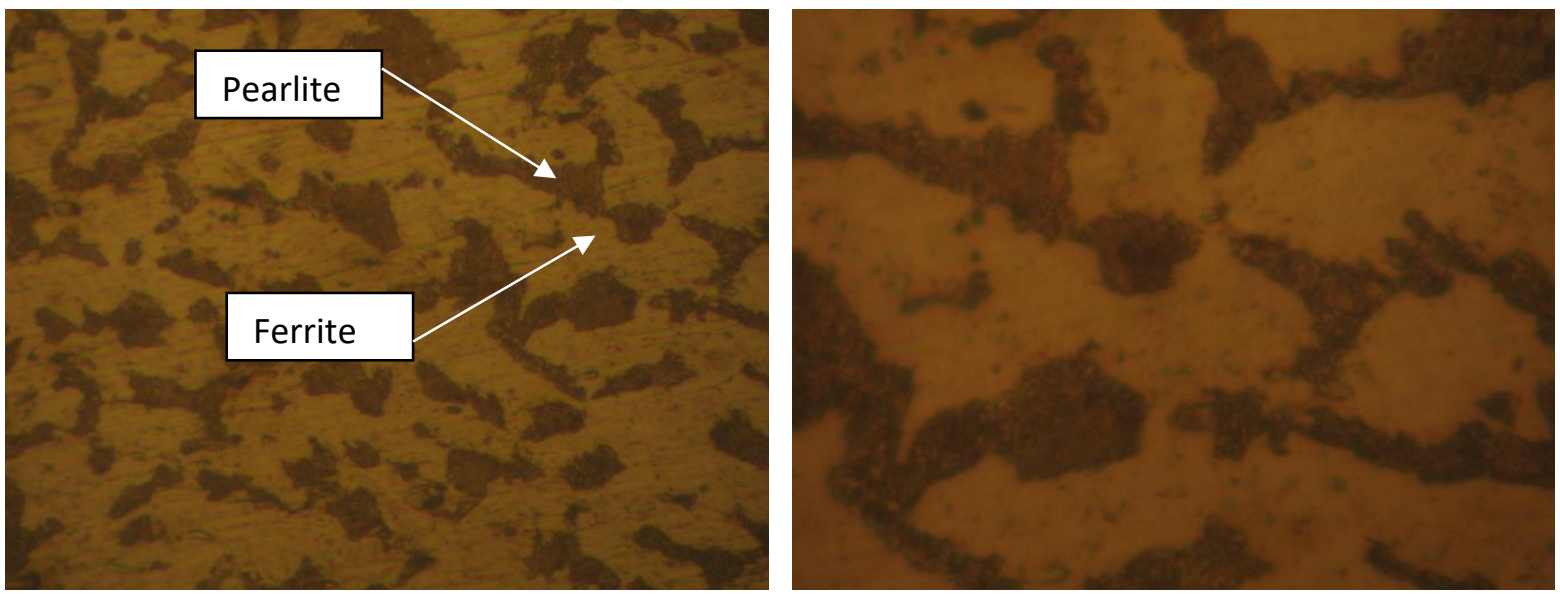

Figure 2. Microstructure of the steel before the welding [magnified 300 times and 600 times].

The dark areas correspond to pearlite consisting of $10 \%$ cementite $\left(\mathrm{Fe}_{3} \mathrm{C}\right)$ and $90 \%$ ferrite. The yellowish zone corresponds to ferrite. Moreover, the micro graphical observation enables us to estimate that the pearlite content is $40 \%$ of the global surface, and the rest corresponds to the ferrite $\alpha$. The examination of the $\mathrm{Fe}-\mathrm{C}$ binary diagram of Figure 3 enables us to determine carbon amount. So, the rate of carbon is 0.8 (wt \%) for this sample before welding. According to the binary diagram, the studied sample is ranked in the hypoeutectoid domain.

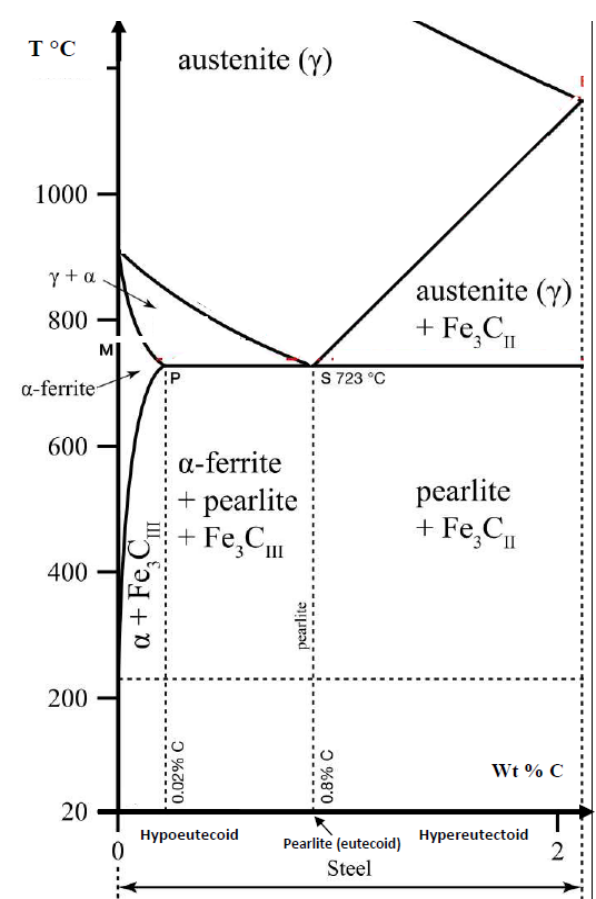

Figure 3. binary diagram of the steel of carbon weight below $2 \%$. 
After obtaining the initial observation of the microstructure of the steel before welding, in Figure 3, the present welded samples show a change in microstructure due to the energy. At this stage, it is worthy of describing the principle used during this operation to understand the influence of the provided energies on macrographic and microstructure. This process generates heat by an electric arc struck between an electrode and the workpiece, creating simultaneously a melt between this later and the ionized electrode metal $\left(500\right.$ to $\left.800^{\circ} \mathrm{C}\right)$. For the flat steel welding, the intensity setting can be as follows:

$$
\mathrm{I}_{\text {average }}=\mathrm{K}(\varphi-1)[\mathrm{A}]
$$

where $\mathrm{K}$ stands for the generator and $\mathrm{K}=\mathrm{Cte}=50 . \mathrm{I}_{\max }=\mathrm{K} . \varphi$ and $\varphi=$ diameter of the electrode $[\mathrm{mm}]$.

The operational welding facts are summarized in Table 1, where the welding occurred without preheating.

Table 1. Operational welding facts.

\begin{tabular}{l|l}
$\begin{array}{l}\text { Welding process: arc welding with electrode (Diameter } \\
=\mathbf{2 . 5} \mathbf{~ m m} \text { ) }\end{array}$ & $\begin{array}{l}\text { Post of welding: } \\
\text { PHILIPS, Type PZ 2038 / 02 } \\
\text { Atelier de soudage : Traitement Mécanique-GMD- } \\
\text { ENIM }\end{array}$ \\
\hline $\begin{array}{l}\text { Base metal: 316L }(\text { AISI) } \\
\text { Supplier: fonderie \& aciers du Maroc }\end{array}$ & Filler metal: 316L (AISI) \\
\hline &
\end{tabular}

The welding energy is defined as the energy transferred per length unit of the weld, that is to say, the displacement of the heat source. The welding energy is calculated by the following formula:

$$
\mathrm{E}\left(\frac{\mathrm{J}}{\mathrm{cm}}\right)=\frac{\mathrm{U}(\mathrm{V}) \times \mathrm{I}(\mathrm{A})}{\mathrm{V}\left(\frac{\mathrm{cm}}{\mathrm{s}}\right)}
$$

The welding speed is given by:

$$
\mathrm{V}\left(\frac{\mathrm{cm}}{\mathrm{s}}\right)=\frac{\mathrm{l}(\mathrm{cm})}{\mathrm{t}(\mathrm{s})}
$$

where the dissipated energy is expressed by

$$
\mathrm{E}_{\mathrm{d}}=\mathrm{E} . \eta
$$

The $\eta$ stands for the yield and $\mathrm{E}$ is expressed in (1).

The equivalent energy is given by:

$$
\mathrm{E}_{\mathrm{eq}}=\mathrm{E} \cdot \eta \cdot \mathrm{k}
$$

where $k$ is a correction coefficient that considers the geometry of the joint to be welded, in the present study $k=0.67$, since the penetration area $\approx 90^{\circ}$ for a geometry of the joint in Y. See, Figure 1 (b), the welding energy findings for all samples are summarized in Table 2. 


\begin{tabular}{|c|c|}
\hline Sample & $E\left(\frac{J}{c m}\right)$ \\
\hline 1 & 18302.51 \\
\hline 2 & 20183.58 \\
\hline 3 & 28952.00 \\
\hline 4 & 40906.50 \\
\hline 5 & 63517.70 \\
\hline
\end{tabular}

Based on this process, it is clear that the macrography of the samples has been changed (Figure 5). Generally, the macrography allows revealing the different areas with a contrast of each weld according to (XY) plane. It aimed to reveal the structure of austenite, which is considered the majority phase in the melted zone (MZ). Three different zones have been stated namely, melted zone (MZ), heated affected zone (HAZ), and base metal (BM) (Figure 4).

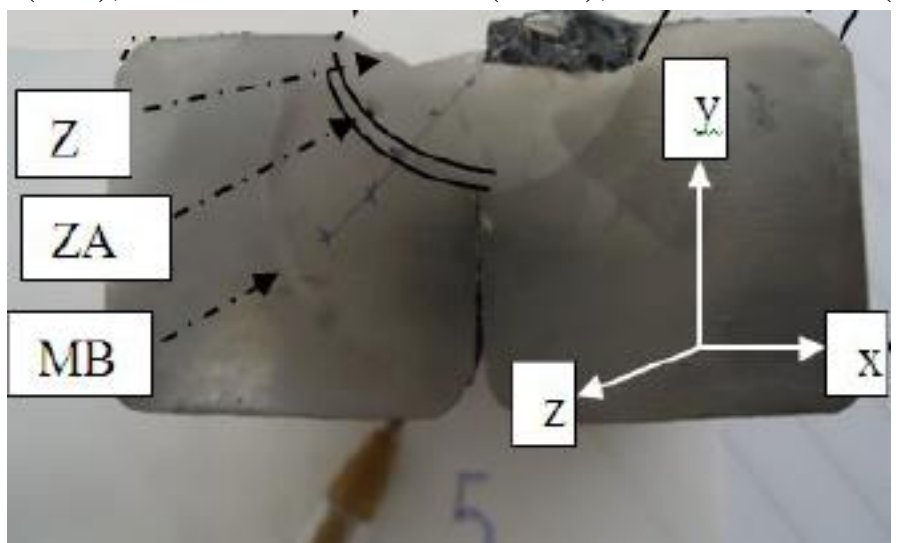

Figure 4. Example of sectional plan XY for macrographic observation.
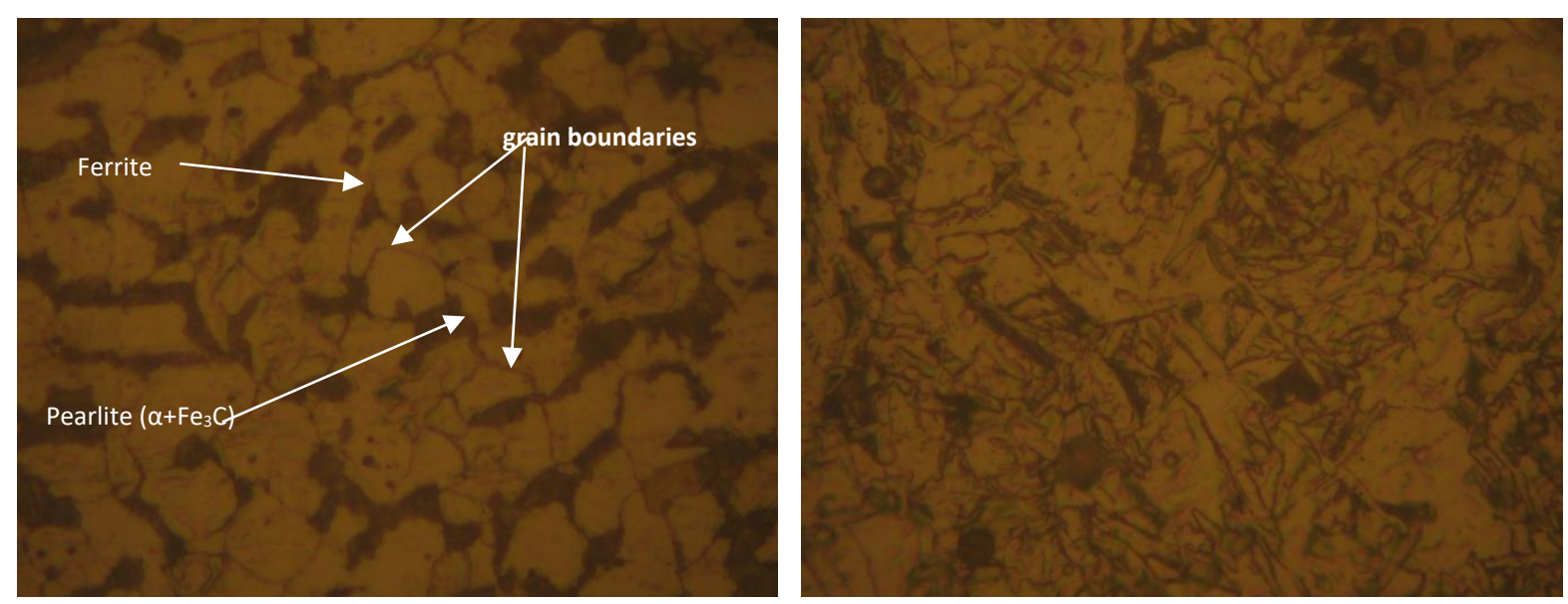

(a)

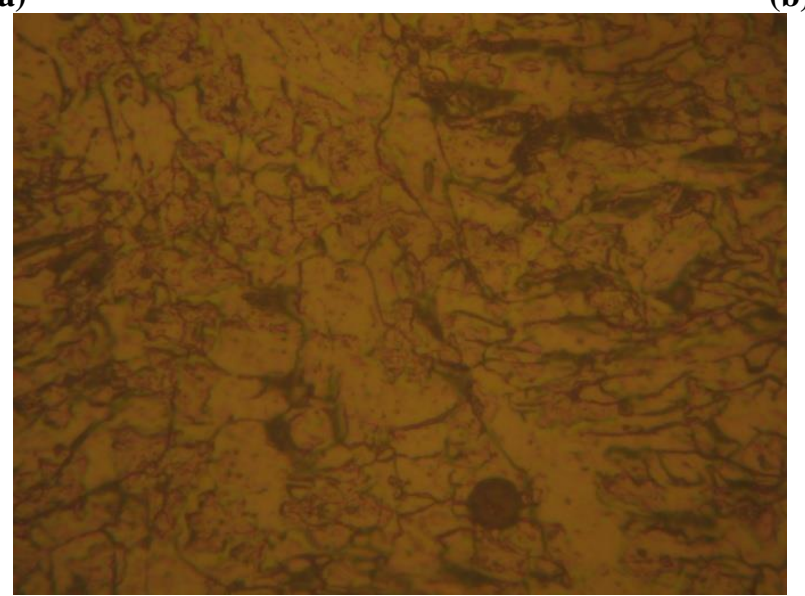

(c)

Figure 5. Sample 1 - microstructure of the steel after welding [magnified 300 times]. 


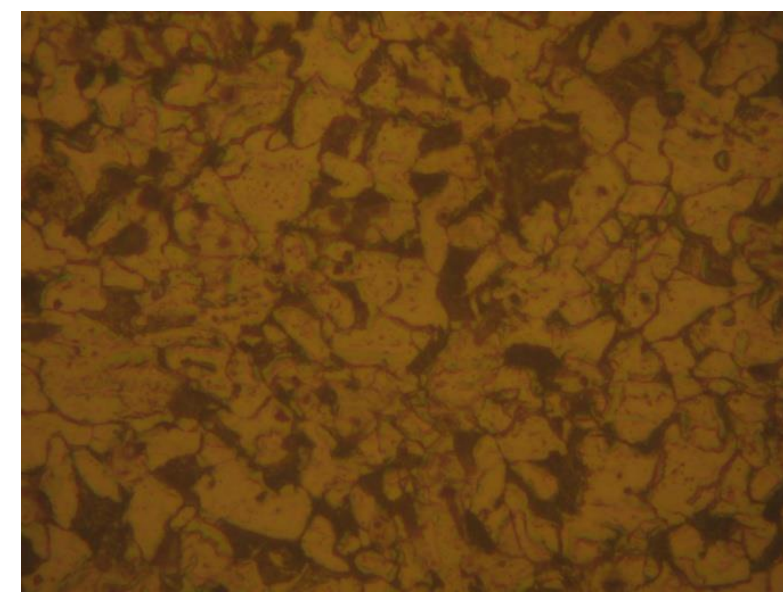

(a)

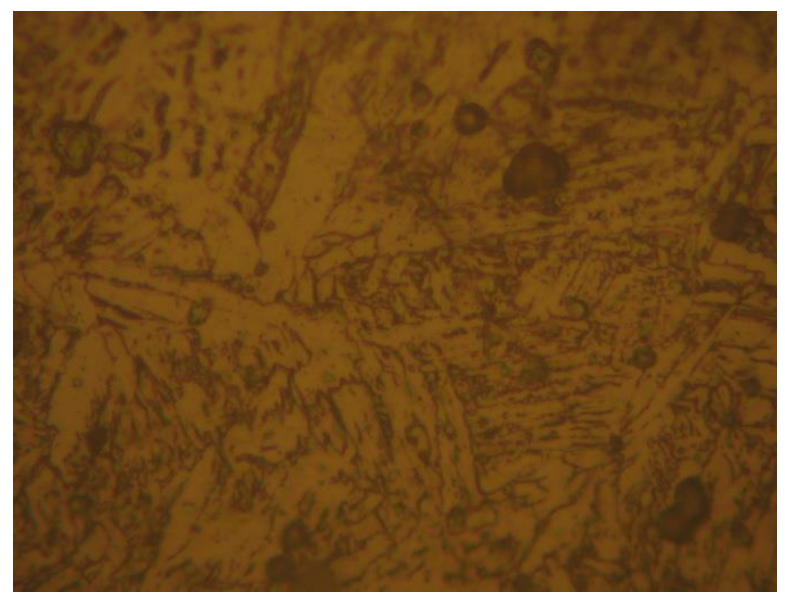

(b)

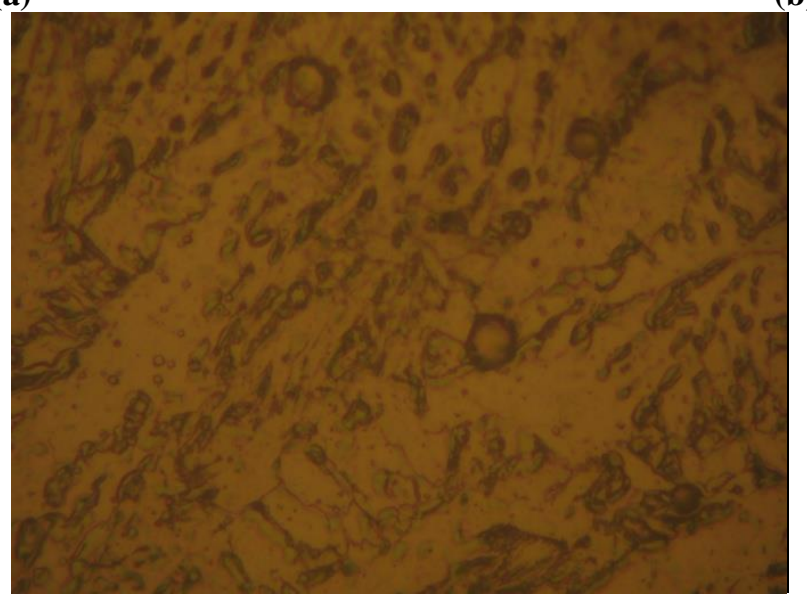

(c)

Figure 6. Sample 2 - microstructure of the steel after welding [magnified 300 times].

Metallographic observation with the optical microscope is a basic method to study the structure. The preparation of the samples must be carried out in such a way as to avoid any structural modification due to the heating or hardening of the material. The following figures taken on XY plans for the five samples show some changes brought by the weld.

At Base metal, as an example, Figures 5 (a) and 6 (a) compared to Figure 2 show the presence of a hypoeutectoid structure, where the amount of carbon is $\% \mathrm{C}<0,8$, the grain boundaries appear, and the sizes of these grains begin to decrease due to the thermal cycling of the welded samples.

For the heated affected zone, the observations of the different welds indicated that microstructures are in the form of Widmanstatten patterns, which do not take the same areas due to the different welding energies of each sample (Figures 5 (b) and 6 (b)). Also, the grains elongation and direction of the welded are not the same compared to the form of that initial steel (Figure 2).

The melted zone microstructure of the Figures 5 (c) and 6 (c) is different from the microstructure of the HAZ. It has a solidification aspect, composed of two phases ( $\gamma$ austenite and $\alpha$ ferrite). However, the energy of welding plays a very important role in terms of grain size. Each zone revealed in micrography by a particular contrast corresponds to a set of grains having a common orientation depends on the direction of cooling and the impact of the welding position. Therefore, the differentiation of this aspect shows a variation in the energy of the weld. 
The hardness of a material defines the resistance of the surface of the sample to the penetration of a harder body using a ball or the tip of a durometer. There are a wide variety of possible hardness tests. They are widely used in quality control to compare or estimate the strength or stiffness of materials [21]. For this, the Vickers hardness is a useful principle to measure the resistance of the different samples; according to the following relation [22]:

$$
\mathrm{H}_{\mathbf{V}}=2 \mathrm{~F} \cdot \frac{\sin \left(\frac{136^{\circ}}{2}\right)}{\mathrm{g} \cdot \mathrm{d}^{2}} \approx \frac{0,189 \cdot \mathrm{F}}{\mathrm{d}^{2}}
$$

where

$$
\begin{aligned}
& \mathrm{H}_{\mathbf{V}}: \text { Vickers hardness } \\
& \text { F }: \text { Applied force }[\mathrm{N}] \\
& \text { d }: \text { Average footprint diagonals }[\mathrm{mm}] \\
& \text { g : Gravitational acceleration }\left[\mathrm{m}_{\mathrm{s}} \mathrm{s}^{-2}\right]
\end{aligned}
$$

From the measurements taken for each weld, the hardness decreases from $\mathbf{M Z}$ to $\mathbf{B M}$ for all the samples, see Figure 7. This can be explained by the thermal fact of the energy dissipated $\boldsymbol{E}_{\boldsymbol{d}}$ on the microstructure of the grains and joints and their structural reorganizations, which depend on the impact of the heat flux during welding. So, the hardness of the sample is higher where its grains are being finer, too [23-24]. The elastic limit, for example, depends on the inverse of the square root of the grain size "d" according to the Hall-Petch formula:

$$
\sigma=\sigma_{0}+\frac{\mathrm{k}}{\sqrt{\mathrm{d}}}
$$

where $\sigma_{0}$ and $\mathrm{k}$ are constants characteristic of the material. Note that Vickers-microhardness was tested using Vickers- durometer having a load of $25 \mathrm{~g}$, the microhardness of the samples were tested according to the testing standard followed by the guidelines of ISO 6507-1: 2005(E) [25]. The values of hardness denoted $\mathrm{H}_{\mathbf{V}}$, are read on the screen as depicted in Figure 7. They are presented as curves gathered in Figure 8.

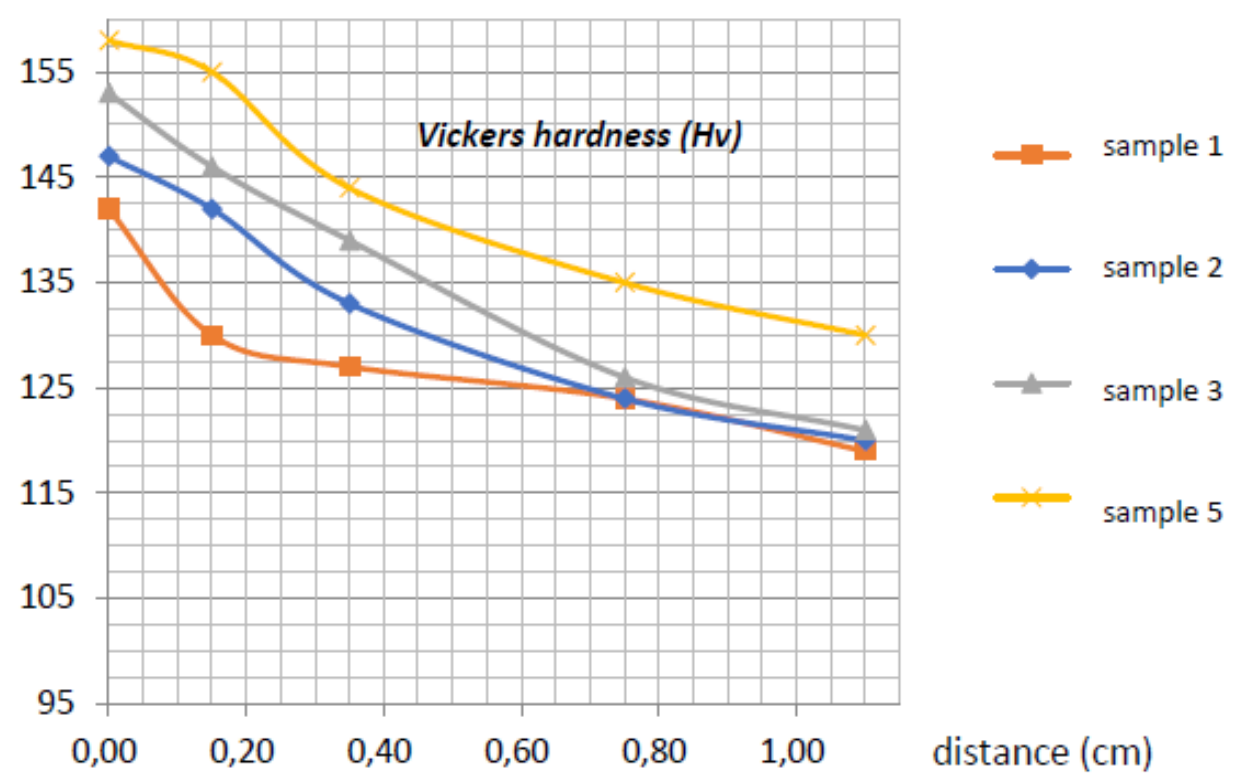

Figure 7. Vickers hardness values in terms of the distance on the welded sectional plan XY (the $0 \mathrm{~cm}$ sets on MZ). 
To highlight the importance of the energy on the hardness of the base metal after welding, it is useful to measure the hardness at the diagonal points in terms of the welded energy from $\mathrm{MZ}$ to $\mathrm{BM}$, Figure 8. It is clear that the hardness increase is considerable when the energy augmentation for all simples. Consequently, the weld's energy directly influences the macro, microstructure, and mechanical behavior of the material.

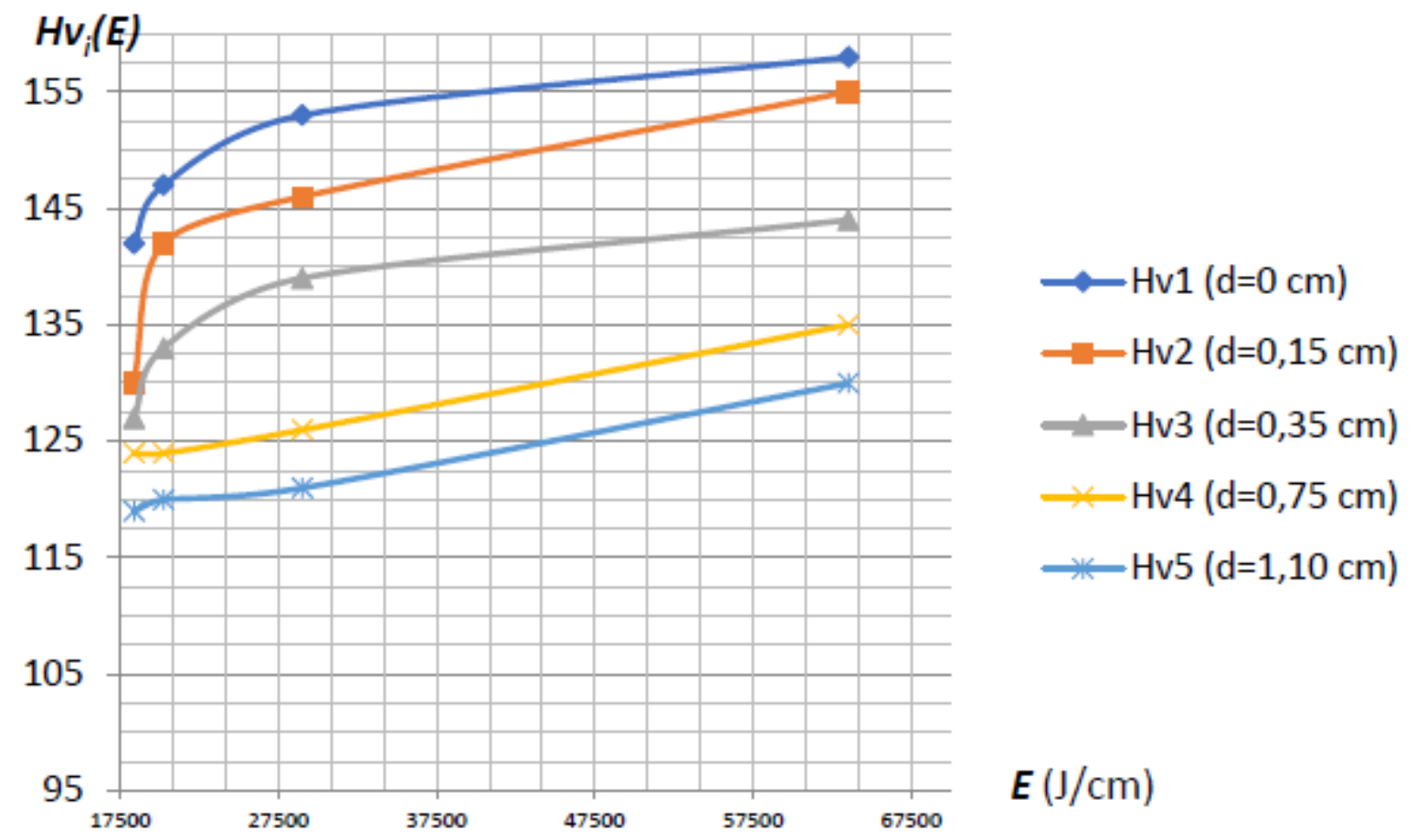

Figure 8. Vickers hardness comparison in terms of the welded energy connected to the samples, measured at the same point.

\section{Results and Discussion}

Corrosion is defined as the deterioration of a material, usually a metal, because of its reaction to the environment [26]. Corrosion inhibitors are widely used in industry to reduce the corrosion rate of metals that are in contact with aggressive environments.

There are two types of corrosion inhibitors (organic and inorganic). Due to growing ecological awareness and strict environmental regulations, as well as the inevitable trend towards sustainable and environmentally friendly processes, attention has now been focused on the development of nontoxic alternatives to coatings so far [1,27]. Many research reports have reported on the polymeric coating as corrosion fight in different aggressive environments [28-30]. In this study, the epoxy/2wt \% Alumina coating is used to resist the corrosion of the five welded steel in $1 \mathrm{M} \mathrm{HCl}$ media.

\subsection{Electrochemical and potentiodynamic polarization measurements.}

The electrochemical measurements were carried out using a Volta lab (TacusselRadiometer PGZ 300) potentiostat and controlled by a Tacussel corrosion analysis software model (Voltamaster 4) under static conditions. The corrosion cell used had three electrodes. The reference electrode was a saturated calomel electrode (SCE). A platinum electrode was used as an auxiliary electrode with a surface area of $1 \mathrm{~cm}^{2}$. The working electrode is welded steel 316L.

After measuring the open circuit $\boldsymbol{E}_{\text {ocp }}$ of the electrode, electrochemical measurements were performed. All electrochemical tests have been performed in aerated solutions at $303 \mathrm{~K}$. 


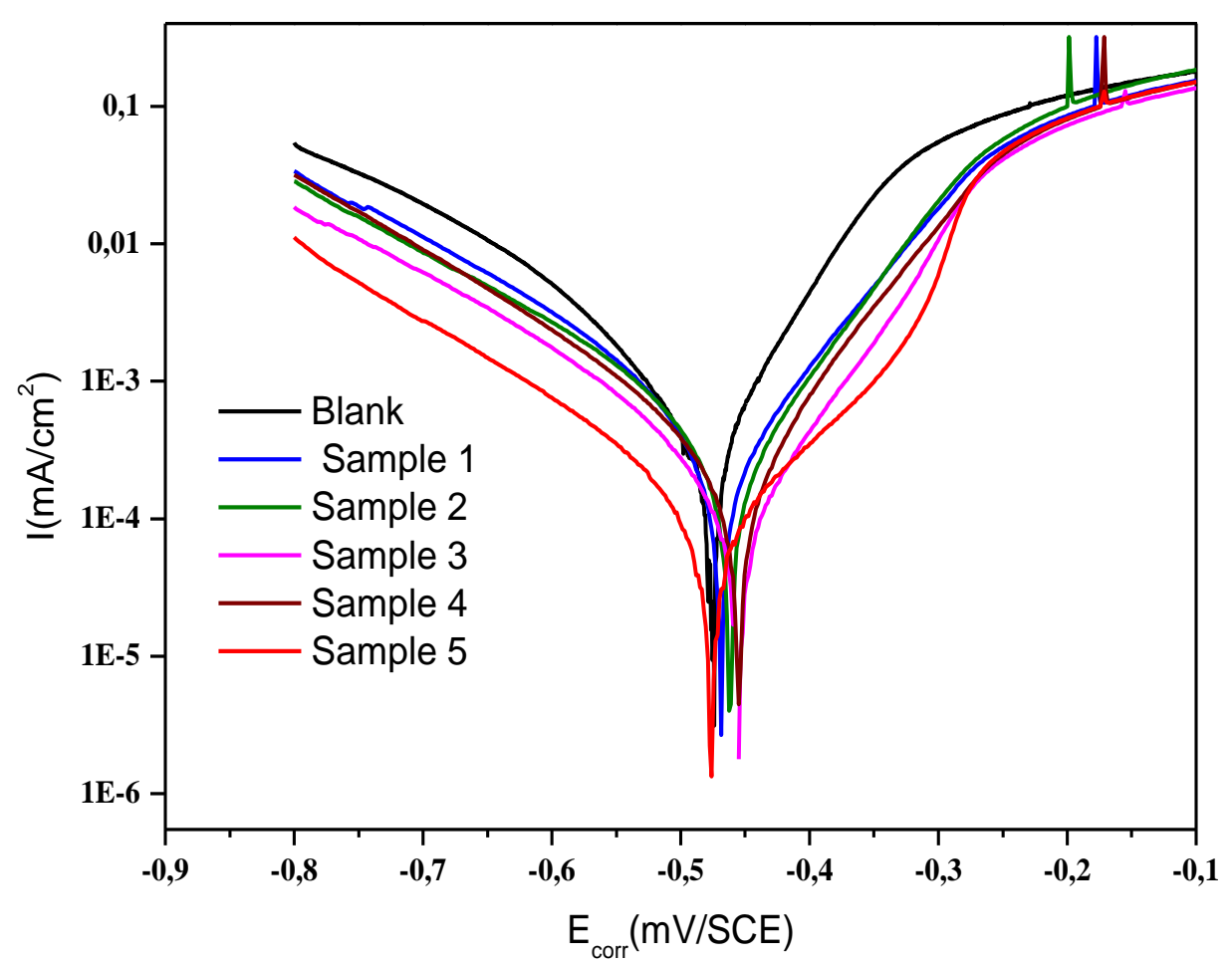

Figure 9. Potentiodynamic polarization test on blank and epoxy/2wt\% Alumina coated welded samples in $1 \mathrm{M} \mathrm{HCl}$ solution.

Figure 9 showed the decrease in corrosion current density $\left(I_{\text {corr }}\right)$ with the coating compared to the blank solution, this is due to coating protection on metal surface which reduces the rate of corrosion current density and increases inhibition efficiency [31-33]. It was noticed an important difference between the current densities of the five coated samples, and this is more likely due to the difference in microstructure which is deeply dependent on the welding energy of each sample. Indeed, the welding energy is increasing from sample 1 to sample 5 with many orders of magnitude. The $I_{\text {corr }}$ can be obtained by extrapolating the Tafel lines to the corrosion potential, and the efficiency $(\eta \%)$ values were calculated from the relation $[1$, 8]:

$$
\eta(\%)=\frac{I_{\text {corr }}^{0}-I_{\text {corr }}}{I_{\text {corr }}^{0}} \times 100
$$

where $I_{\text {corr }}$ presents corrosion current density value with the coating and $I_{\text {corr }}^{0}$ is the corrosion current density value without coating.

Nyquist plots were also drawn from these experiments. The coating efficiency was calculated from the charge transfer resistance values using the following equation [8,34]:

$$
\eta(\%)=\frac{R_{c t(i n h)}-R_{c t}}{R_{c t(i n h)}} \times 100
$$

where, $R_{c t(i n h)}$ and $R_{c t}$ are the values of charge transfer resistance with and without the coating in $1 \mathrm{MHCl}$ solution, respectively. 


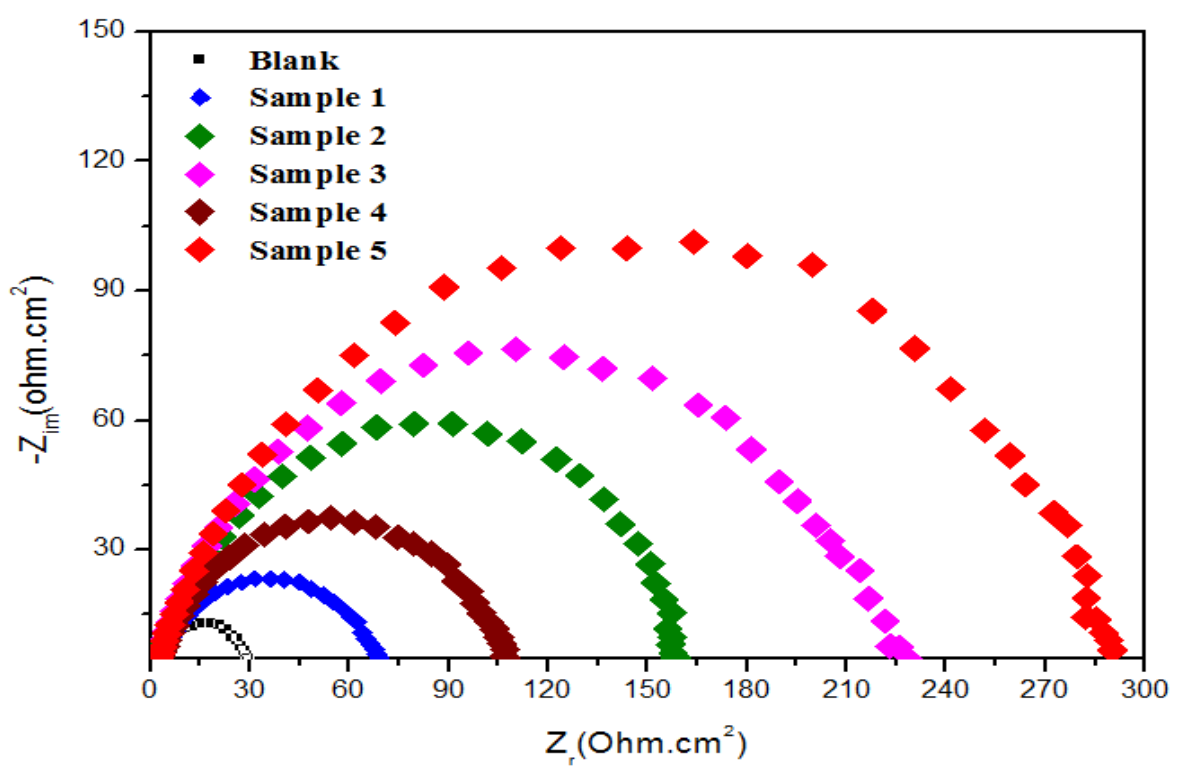

Figure 10. Nyquist plot of welded steel in $1 \mathrm{M} \mathrm{HCl}$ blank solution and epoxy/2wt $\%$ Alumina coated welded steels in $1 \mathrm{M} \mathrm{HCl}$ solution.

Nyquist plots of welded samples immersed in $1 \mathrm{M} \mathrm{HCl}$ without and with coating are shown in Figure 10. A high-frequency depressed charge transfer semicircle is observed [35, 36]. Figure 10 shows that the impedance spectra are not perfect semicircles, and the depressed capacitive loop corresponds to the heterogeneity of the surface, which can be the result of the roughness.

\subsection{Scanning electron microscope analyses}

Surface morphology was recorded to investigate the changes that occurred on the welded samples' surface after $2 \mathrm{~h}$ immersion in $1 \mathrm{M} \mathrm{HCl}$ before and after epoxy/2wt\% Alumina coating. Figure 11 (a) represents the micrograph obtained of polished welded steel without being exposed to the corrosive environment, while Figure 11 (b) presents the micrograph obtained for a carbon steel sample after exposure to the blank solution, it showed strongly damaged welded steel surface due to the formation of corrosion products after immersion in 1 $\mathrm{M} \mathrm{HCl}$ solution. Figure 11 (c) exhibits a welded steel surface SEM image after immersion in 1 $\mathrm{M} \mathrm{HCl}$ with epoxy/ alumina coating. It could be seen that no pits and cracks are observed in the micrographs after immersion of welded steel in $1 \mathrm{M} \mathrm{HCl}$ with deposited coating except polishing lines. Thus, it revealed the presence of a good protective film upon adsorption of the deposited film on the metal surface, which was responsible for the inhibition of corrosion.
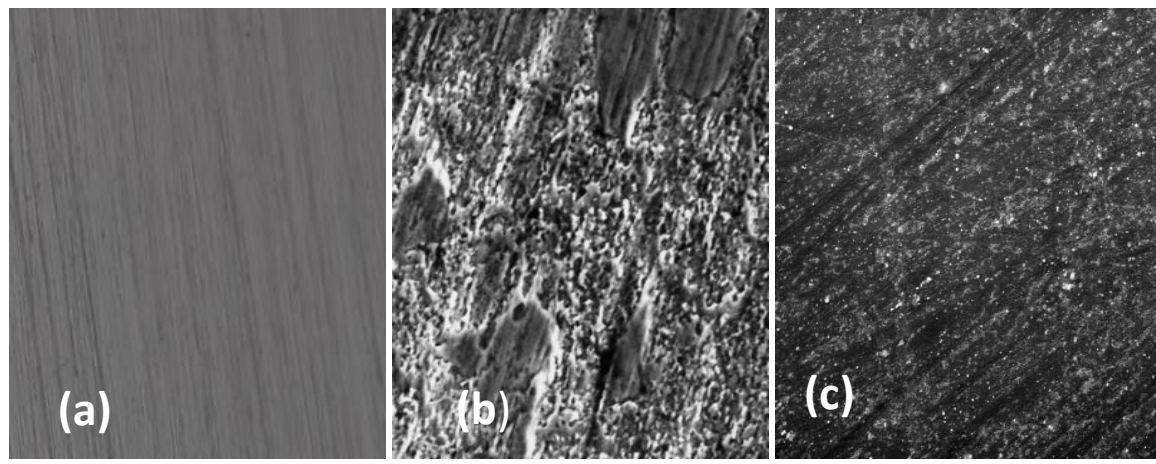

Figure 11. SEM micrographs of (a) a bare steel surface; (b) corroded steel surface and (c) epoxy/Alumina coated steel surface [x200]. 


\subsection{Correlation between hardness and electrochemical properties.}

The energy of welded zone plays an important role in the increase of hardness. It was found in the above section that increasing welding energy gives rise to micro-hardness values, and these laters seem to have a deep impact on the electrochemical tests which were performed upon the five samples by Epoxy/2wt\% Alumina coating in $1 \mathrm{M} \mathrm{HCl}$ media. According to the electrochemical studies, it was proved that the current density of the coated surfaces of the five samples shows a noticeable decrease with the increase of welding energy. Also, impedance spectroscopy confirmed the same evolution by exhibiting an increase of resistance of the deposited thin film with the increase of welding energy, which is more likely due to the stiffness improvement of the samples, which lead to ameliorated cohesion force resulting in excellent absorption of the protective film on the welded steel surface.

\section{Conclusions}

This work is devoted to studying the effect of welding energy on industrial low carbon steel 316L. In the center of the weld zone, the microstructures in different zones are different from the heat-affected zone. The HAZ contains Widmanstatten ferrite, large grains of ferrite, and colonies of pearlite. Moreover, micro-hardness results evidenced that maximum hardness values are situated in the fifth sample's melted metal.

The fourth section of this work consists of studying corrosion inhibition efficiency of Epoxy $/ 2 \mathrm{wt} \%$ Alumina was determined by electrochemical and surface morphology. The potentiodynamic polarization data indicated that the current density decreases with the increase of welding energy. Electrochemical impedance spectroscopy data reveals an increase in $R_{c t}$ values that accounted for good inhibition efficiency.

\section{Funding}

This research received no external funding.

\section{Acknowledgments}

The authors would like to thank the support of Mrs. Saloua Rzaoudi, Ms. Khadija Ziat and "Catedra CONACYT project number 746, and the ECOSUR Chetumal for the SEM images, Mexico". Our thanks are extended to Mr. Mohammed Ali Errachid from "Economy Management, Mohammed 5 University of Rabat, Faculty of Law, Economics and Social Sciences-Souissi, Rabat, Morocco" and Ms. Maryem Errachid from "Universität Paderborn, Warburger Straße 100, 33098 Paderborn, Germany" to accept the language revision. We are warmly grateful the professor Mohamed Ghaleb from "Lycée Oulad Youssef, Délégation Béni Mellal, Région Béni Mellal—Khénifra, Maroc" to discuss the DATA of this work. Also, we are grateful to Professor Y. Lakhal, FZ. Baghli, M. Benchagra, A. Balouki, M. Aqil, and A. Boudaoud who are the founders of "Engineering and Applied Physics Team (EAPT) of Sultan Moulay Slimane University, Beni Mellal, Morocco" for the fruitful discussion and the provided expertise.

\section{Conflicts of Interest}

No conflict exists between the authors. 


\section{References}

1. Ziat, Y.; Hammi, M.; Zarhri, Z.; Laghlimi, C. Epoxy coating modified with graphene: A promising composite against corrosion behavior of copper surface in marine media. J. Alloys Compd 2020, 820, 153380, https://doi.org/10.1016/j.jallcom.2019.153380.

2. Mandour, H. S.; Abouel-Enein, S. A.; Morsi, R. M.; Khorshed, L. A. Azo ligand as new corrosion inhibitor for copper metal: Spectral, thermal studies and electrical conductivity of its novel transition metal complexes. J. Mol. Struct 2021, 1225, 129159, https://doi.org/10.1016/j.molstruc.2020.129159.

3. Kozlica, D. K; Kokalj, A.; Milošev, I. Synergistic effect of 2-mercaptobenzimidazole and octylphosphonic acid as corrosion inhibitors for copper and aluminium-An electrochemical, XPS, FTIR and DFT study. Corros. Sci. 2021, 182, 109082, https://doi.org/10.1016/j.corsci.2020.109082.

4. Hamidah, I.; Solehudin, A.; Hamdani, A.; Hasanah, L.; Khairurrijal, K.; Kurniawan, T.; Hammouti, B. Corrosion of copper alloys in $\mathrm{KOH}, \mathrm{NaOH}, \mathrm{NaCl}$, and $\mathrm{HCl}$ electrolyte solutions and its impact to the mechanical properties. Alex. Eng. J. 2021, 60, 2235-2243, https://doi.org/10.1016/j.aej.2020.12.027.

5. Samide, A.; Iacobescu, G. E.; Tutunaru, B.; Iordache, S. Silver nanoparticles/polyvinyl alcohol film: studies of thermal characterization, AFM and corrosion protection by electrodeposition on 304L stainless steel. $J$ Therm Anal Calorim 2021, 1-11, https://doi.org/10.1007/s10973-020-10444-0.

6. Anjum, M.J.; Zhao, JM.; Asl, V.Z. Green corrosion inhibitors intercalated Mg:Al layered double hydroxide coatings to protect Mg alloy. Rare Met 2021, 40, 2254-2265, https://doi.org/10.1007/s12598-020-01538-7.

7. Verma, D.K.; Dewangan, Y.; Dewangan, A.K. Heteroatom-Based Compounds as Sustainable Corrosion Inhibitors: An Overview. J Bio Tribo Corros 2021, 7, 15, https://doi.org/10.1007/s40735-020-00447-7.

8. Ziat. Y.; M. Hammi. An experimental evaluation of inhibiting corrosion effect of phosphate glass on mild steel in acidic solution, Mater. Res. Express 2019, 6, 086567, https://iopscience.iop.org/article/10.1088/20531591/ab1a4b/meta.

9. Kaur, J.; Daksh, N.; Saxena, A. Corrosion Inhibition Applications of Natural and Eco-Friendly Corrosion Inhibitors on Steel in the Acidic Environment: An Overview. Arab J Sci Eng 2021, https://doi.org/10.1007/s13369-021-05699-0.

10. Nahlé, A.; Salim, R.; El Hajjaji, F.; Aouad, M. R.; Messali, M.; Ech-Chihbi, E.; Taleb, M. Novel triazole derivatives as ecological corrosion inhibitors for mild steel in $1.0 \mathrm{M} \mathrm{HCl}$ : experimental \& theoretical approach. RSC Advances 2021, 11, 4147-4162, https://doi.org/10.1039/D0RA09679B.

11. Hajjaji, F. E.; Salim, R.; Taleb, M.; Benhiba, F.; Rezki, N.; Chauhan, D. S.; Quraishi, M. A. Pyridiniumbased ionic liquids as novel eco-friendly corrosion inhibitors for mild steel in molar hydrochloric acid: Experimental \& computational approach. Surf. Interfaces 2021, 22, 100881, https://doi.org/10.1016/j.surfin.2020.100881.

12. Kasprzhitskii, A.; Lazorenko, G.; Nazdracheva, T.; Yavna, V. Comparative Computational Study of L-Amino Acids as Green Corrosion Inhibitors for Mild Steel. Computation 2021, 9, 1, https://doi.org/10.3390/computation9010001.

13. Sun, Y.; Jiang, K.; Liang, Y.; Zhao, O. Experimental and numerical studies of high-chromium stainless steel welded I-section beam-columns. Eng. Struct 2021, 236, 112065 , https://doi.org/10.1016/j.engstruct.2021.112065.

14. Su, A.; Liang, Y.; Zhao, O. Experimental and numerical studies of S960 ultra-high strength steel welded Isection columns. Thin-Walled Struct. 2021, 159, 107166, https://doi.org/10.1016/j.tws.2020.107166.

15. Mičian, M.; Frátrik, M.; Kajánek, D. Influence of Welding Parameters and Filler Material on the Mechanical Properties of HSLA Steel S960MC Welded Joints. Metals 2021, 11, 305, https://doi.org/10.3390/met11020305.

16. Sriba, A.; Vogt, J. B.; Amara, S. E. Microstructure, micro-hardness and impact toughness of welded austenitic stainless steel 316L. Trans Indian Inst Met 2018, 71, 2303-2314, https://doi.org/10.1007/s12666-018-13624.

17. Ke, C.; Li, Y.; Liu, X.; Gou, F.; Duan, X.; Zhao, Y. Application of laser induced breakdown spectroscopy for fast depth profiling analysis of type 316 stainless steel parts corroded by liquid lithium. Fusion Eng. Des. 2018, 136, 1647-1652, https://doi.org/10.1016/j.fusengdes.2018.07.004.

18. Khidhir, G. I.; Baban, S. A. Efficiency of dissimilar friction welded 1045 medium carbon steel and 316L austenitic stainless steel joints. J. Mater. Res. Technol. 2019, 8, 1926-1932, https://doi.org/10.1016/j.jmrt.2019.01.010. 
19. Efimenko, L.A.; Kapustin, O.E.; Ponomarenko, D.V. Specifics of Structure Formation and Properties of Welded Joints Obtained by Laser-Hybrid Welding of Longitudinal Pipe Joints. Metallurgist 2021, 64, 11711178. https://doi.org/10.1007/s11015-021-01102-3.

20. Behera, S. K.; Kumar P, A.; Dogra, N.; Nosonovsky, M.; Rohatgi, P. Effect of microstructure on contact angle and corrosion of ductile iron: Iron-graphite composite. Langmuir 2019, 35, 16120-16129, https://doi.org/10.1021/acs.langmuir.9b02395.

21. Ghorbal, G. B.; Tricoteaux, A.; Thuault, A.; Louis, G.; Chicot, D. Comparison of conventional Knoop and Vickers hardness of ceramic materials. J Eur Ceram Soc 2017, 37, 2531-2535, https://doi.org/10.1016/j.jeurceramsoc.2017.02.014.

22. Ahmed, I. I.; Mohammed, A. T.; Abdulkareem, S.; Yahaya, T.; Ambali, I. O.; Bayode, B. L.; Adebisi, J. A. Potential of Cow Horn for Carbonitriding Treatment of Steel. Waste Biomass Valori 2019, 10, 1969-1978, https://doi.org/10.1007/s12649-018-0222-0.

23. Chen, S.; Tseng, K. K.; Tong, Y.; Li, W.; Tsai, C. W.; Yeh, J. W.; Liaw, P. K. Grain growth and Hall-Petch relationship in a refractory HfNbTaZrTi high-entropy alloy. J. Alloys Compd 2019, 795, 19-26, https://doi.org/10.1016/j.jallcom.2019.04.291.

24. Cordero, Z. C.; Knight, B. E.; Schuh, C. A. Six decades of the Hall-Petch effect-a survey of grain-size strengthening studies on pure metals. Int. Mater. Rev 2016, 61, 495-512, https://doi.org/10.1080/09506608.2016.1191808.

25. Fedotkin, A. P.; Laktionov, I. V.; Kravchuk, K. S.; Maslenikov, I. I.; Useinov, A. S. Automatic Processing of Microhardness Images Using Computer Vision Methods. Instrum Exp Tech 2021, 64, 357-362, https://doi.org/10.1134/S0020441221030180.

26. Rosliza, R.; Nik, W. W.; Izman, S.; Prawoto, Y. Anti-corrosive properties of natural honey on Al-Mg-Si alloy in seawater. Curr. Appl. Phys 2010, 10, 923-929, https://doi.org/10.1016/j.cap.2009.11.074.

27. Pandey, V.; Singh, J. K.; Chattopadhyay, K.; Srinivas, N. S.; Singh, V. Influence of ultrasonic shot peening on corrosion behavior of 7075 aluminum alloy. J. Alloys Compd 2017, 723, 826-840, https://doi.org/10.1016/j.jallcom.2017.06.310.

28. Kim, J. Y.; Kim, T.; Suk, J. W.; Chou, H.; Jang, J. H.; Lee, J. H.; Ruoff, R. S. Enhanced Dielectric Performance in Polymer Composite Films with Carbon Nanotube-Reduced Graphene Oxide Hybrid Filler. Small 2014, 10, 3405-3411, https://doi.org/10.1002/smll.201400363.

29. Li, Y.; Yang, Z.; Qiu, H.; Dai, Y.; Zheng, Q.; Li, J.; Yang, J. Self-aligned graphene as anticorrosive barrier in waterborne polyurethane composite coatings. J. Mater. Chem. A 2014, 2, 14139-14145, https://doi.org/10.1039/C4TA02262A.

30. Chang, K. C.; Hsu, C. H.; Lu, H. I.; Ji, W. F.; Chang, C. H.; Li, W. Y.; Tsai, M. H. Advanced anticorrosive coatings prepared from electroactive polyimide/graphene nanocomposites with synergistic effects of redox catalytic capability and gas barrier properties. Express Polym. Lett. 2014, 8, 243-255, https://doi.org/10.3144/expresspolymlett.2014.28.

31. Khamis, A.; Saleh, M. M.; Awad, M. I. Synergistic inhibitor effect of cetylpyridinium chloride and other halides on the corrosion of mild steel in $0.5 \mathrm{M} \mathrm{H}_{2} \mathrm{SO}_{4}$. Corros. Sci. 2013, 66, 343-349, https://doi.org/10.1016/j.corsci.2012.09.040.

32. Singh, A.; Lin, Y.; Liu, W.; Kuanhai, D.; Pan, J.; Huang, B.; Zeng, D. A study on the inhibition of N80 steel in $3.5 \% \mathrm{NaCl}$ solution saturated with $\mathrm{CO}_{2}$ by fruit extract of Gingko biloba. J Taiwan. Inst. Chem. Eng 2014, 45, 1918-1926, https://doi.org/10.1016/j.jtice.2014.02.001.

33. Ahamad, I.; Prasad, R.; Quraishi, M. A. Thermodynamic, electrochemical and quantum chemical investigation of some Schiff bases as corrosion inhibitors for mild steel in hydrochloric acid solutions. Corros. Sci 2010, 52, 933-942, https://doi.org/10.1016/j.corsci.2009.11.016.

34. Ziat, Y.; Hammi, M.; Laghlimi, C.; A. Moutcine. Investment casting of leaded brass: Microstructure microhardness and corrosion protection by epoxy coating, Materialia 2020, 12, 100794, https://doi.org/10.1016/j.mtla.2020.100794.

35. Şafak, S.; Duran, B.; Yurt, A.; \& Türkoğlu, G. Schiff bases as corrosion inhibitor for aluminium in $\mathrm{HCl}$ solution. Corros. Sci 2012, 54, 251-259, https://doi.org/10.1016/j.corsci.2011.09.026.

36. Gerengi, H.; Darowicki, K.; Slepski, P.; Bereket, G.; Ryl, J. Investigation effect of benzotriazole on the corrosion of brass-MM55 alloy in artificial seawater by dynamic EIS. J Solid State Electrochem 2010, 14, 897-902, https://doi.org/10.1007/s10008-009-0923-1. 